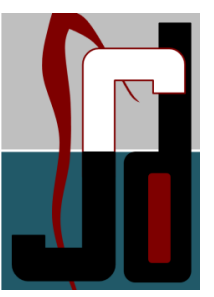

GASE REPORT

\title{
Zucchellie's Technique with GTR Membrane for Multiple Gingival Recession \\ Coverage
}

Jananni. $\mathrm{M}^{1}$, Sivaramakrishnan. $\mathrm{M}^{2}$, Gubernath $\mathrm{U}^{3}$, Anitha Logarangini ${ }^{4}$, Lakshmi Priya ${ }^{5}$

ABSTRACT: Gingival recession associated with dentinal hypersensitivity is one of the commonest issues addressed by the periodontist. The treatment choice for these cases should address biological as well as patient chief complaint. Coronally advanced flaps for root coverage are the most commonly used technique for multiple teeth recessions. This case report describes a case of Class I gingival recession due to faulty brushing technique associate with dentinal hypersensitivity treated with Zucchelli's modification of conventional coronally advanced flap with GTR membrane.

Key words: zucchellie's technique, GTR membrane, gingival recession

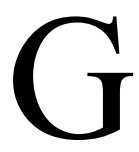

ingival recession is defined as the location of the marginal tissue, apical to the cementoenamel junction (CEJ) with exposure of the root surface. ${ }^{[1]}$ A number of etiological and predisposing factors have been listed in the literature. It can be caused by traumatic injuries (overzealous teeth brushing) and by destructive periodontal disease. ${ }^{[2]}$ Other predisposing factors include tooth malpositioning, alveolar bone dehiscence, thin and delicate marginal tissue covering a nonvascularized root surface, high muscle attachment and frenal pull, occlusal trauma, lip piercing and iatrogenic factors related to reconstructive, conservative periodontologic, orthodontic or prosthetics treatment. ${ }^{[3]}$

Numerous surgical techniques have been proposed for correction of gingival recession. They can be broadly classified into (1) pedicle grafts, (2) free gingival grafts, (3) connective tissue grafts, and (4) the membrane barrier guided tissue regeneration technique. ${ }^{[4]}$ Among the pedicle grafts the coronally advanced flap is the most commonly employed. This case report describes Zucchelli's technique of coronally advanced flap with GTR membrane for root coverage in multiple recession defects.

\section{CASE REPORT}

25 year old female reported to department of Periodontology with the complaint of tooth sensitivity in the maxillary left tooth region for the past 4 months. Sensitivity increases on tooth brushing \& intake of hot \& cold food stuff. On clinical examination Millers class I recession was 
evident on 14, 15, and 16 (Fig. 1). The periodontium was healthy and with no inflammatory signs. The reason for the recession was attributed to faulty vigorous tooth brushing. Scaling and root planing was done and $\mathrm{OHI}$ was given. Proper brushing technique was advised and adequate time was given to change the technique. After 2 months root coverage by Zucchelli's coronally advanced flap with GTR membrane was planned. Informed consent was obtained from the patient.

\section{SURGICAL PROCEDURE}

Zucchelli's technique: New modification of coronally advanced flap for multiple teeth recession coverage. ${ }^{[5]}$ Clinical features of multiple coronal advanced flap are the absence of vertical releasing incisions, a variable thickness, combining areas of split and full thickness and the coronal repositioning of the flap. Another characteristic feature is the oblique submarginal incisions in the interdental area. Incisions are given obliquely connecting the CEJ of one tooth to the gingival margin of the adjacent tooth. ${ }^{[6]}$ (Fig. 2)

Disinfection of the surgical site was done with $2 \%$ betadine. The procedure was carried out under local anesthesia (Lignocaine $\mathrm{HCl}$ with $2 \%$ epinephrine $1: 200,000)$. The incision outline was first marked with a sterile indelible pencil. Oblique

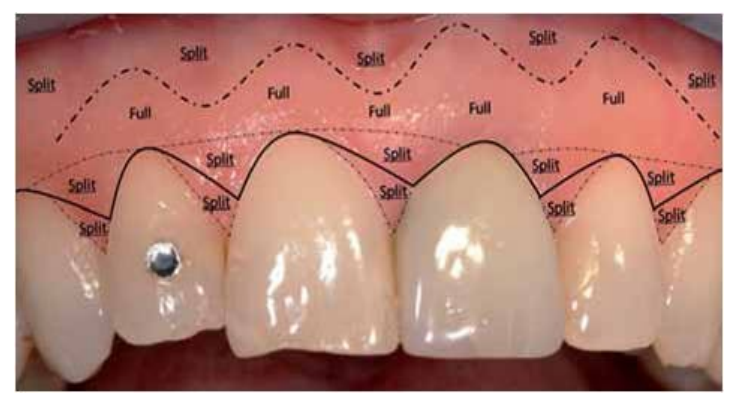

Fig-2: Schematic representation of oblique incision

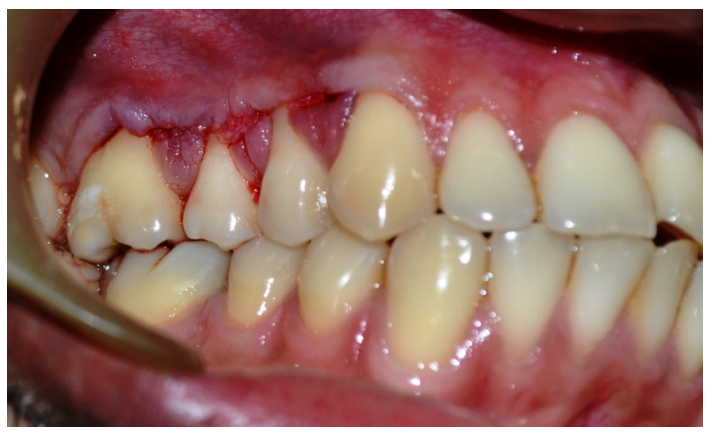

Fig- 3: Oblique horizontal incisions

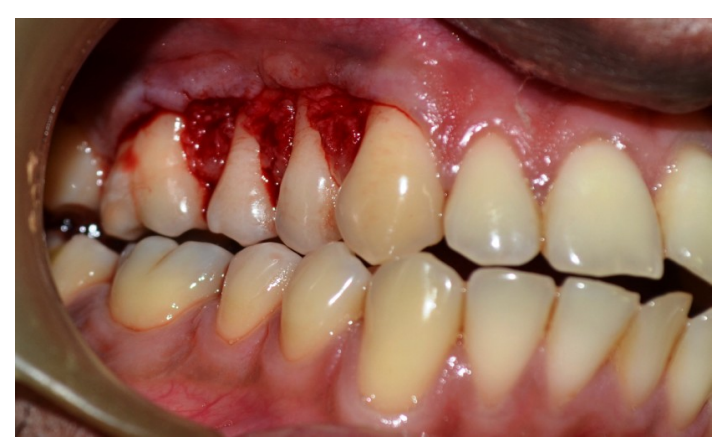

Fig- 4: Interdental papilla deepithelialized and split - full split thickness flap raised 


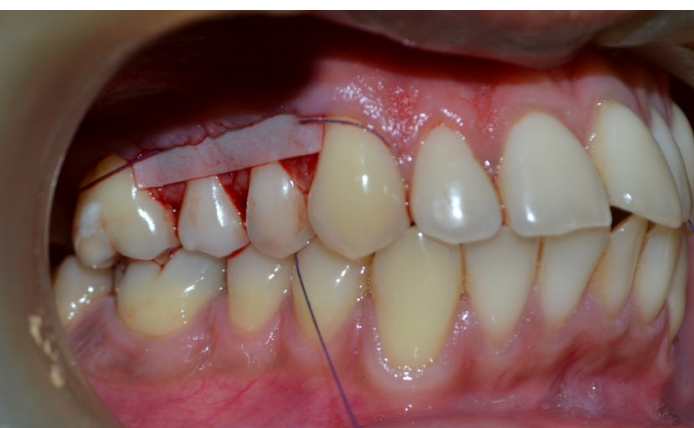

Fig-5: Placement of GTR membrane covering the root surface

horizontal incisions were given connecting the CEJ of one tooth to the gingival margin of the adjacent tooth (Fig. 3). A split thickness flap was reflected till the root exposure and further apically a full thickness flap was raised. Beyond mucogingival junction again a split thickness flap was reflected to ensure adequate coronal displacement. Anatomic interdental papilla was completely deepithelialised to expose the underlying connective tissue and to eliminate the epithelium that might interfere with healing. (Fig. 4)

After flap reflection the root surface was examined for remnant calculus and thorough scaling and root planing was done. Following this a GTR membrane was placed to cover the recession and sutured in place. (Fig. 5) While advancing the flap coronally, surgical papillae were rotated towards the ends of the flap and were displaced on the prepared connective tissue beds of the anatomical papillae. The flap was secured in place with sling sutures. (Fig. 6) This ensured precise adaptation of the flap.

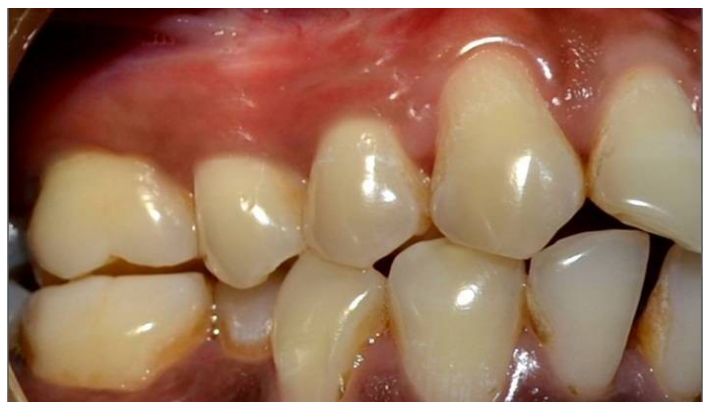

Fig- 6: One year post operative presentation

The surgical site was then covered with periodontal dressing (Coe Pac)

\section{POST OPERATIVE CARE}

The patient was instructed not to remove the pack or disturb the surgical site in any way till the sutures were removed. Other post operative instructions were given. Patient was advised to take antibiotics (Amoxicillin 500mg tds) for 3 days postoperatively. Use of $0.12 \%$ chlorhexidine rinse was also advised. Two weeks post operatively the periodontal dressing and the sutures were removed. Healing was satisfactory and adequate root coverage was obtained. Recall after 6 months reveled stable results and no sensitivity was reported (Fig. 7).

\section{DISCUSSION}

The most important factor in the etiology of dentin hypersensitivity is the exposure of root surfaces from gingival recession. ${ }^{[7]}$ Treatment modality includes an attempt to cover the exposed root surfaces. Over the past decades numerous 
periodontal plastic surgery (PPS) procedures have been described in an attempt to cover exposed root surfaces. ${ }^{[8]}$ Among these methods the most commonly employed is the 'coronally repositioned flap' introduced by Bruiestein in 1970 and modified by Allen \& Miller in $1989 .{ }^{5}$ Zucchelli \& Sanctis modified this technique further in 2000. ${ }^{[9]}$ The case presented here demonstrates Zucchelli's modification of the coronally advanced flap. This new technique has few clinical and biological advantages over the conventional technique. ${ }^{9}$ It is an envelope type of flap without vertical releasing incisions and hence the blood supply is not compromised and there are no unaesthetic scars along incision line. Since it is also a split - full split thickness flap, it guarantees adequate coronal advancement, good anchorage and ample blood supply to the surgical interdental papillae.

In present study using this flap technique adequate root coverage with stable results for over 12 months was achieved. No scar formation was observed and the color match of the tissue was excellent. The chief complaint of hypersensitivity was also resolved completely following the surgery.

\section{CONCLUSION}

This new approach to the coronally advanced technique is very effective for treatment of multiple gingival recessions. Good stable results were observed in terms of root coverage, increased thickness of attached gingiva and resolution of dentinal hypersensitivity associated with gingival recession.

\section{REFERENCES}

1. Wennström JL: Mucogingival therapy. Annals Periodontology, 1996;1: 671-701.

2. Joshipura KJ, Kent RL, DePaola PF: Gingival recession: intraoral distribution and associated factors. Journal of Periodontology, 1994; 65:864-871.

3. Wennstrom JL, Pini Prato GP: Mucogingival therapyperiodontal plastic surgery. In: Clinical Periodontology and implant dentistry. J Lindhe, N P Lang, T Karring, Eds; 4th Edn.; Blackwell Publication, Munksgaard, 2003; pp576-649.

4. M. Goldstein, L. Brayer and Z. Schwartz. A Critical Evaluation of Methods for Root Coverage. Critical Reviews in Oral Biology \& Medicine, 1996. 7(1): 87 -98 .

5. Allen EP, Miller PD. Coronal positioning of existing gingiva: Short term results in the treatment of shallow marginal tissue recession. J Periodontol 1989; $60: 316-319$

6. Baldini. N, Zucchelli. G, Sanctis M. A novel surgical technique for soft tissue management in aesthetic areas of the mouth at implant placement - A case report. Journal de Parodontologie \& d'Implantologie 
Orale 2010, 29(4): 1-8.

7. Watson PJ. Gingival recession. J Dent. 1984;12(1): 29-35

8. Agrawal N, Rosaiah K, Prasad SSV. Periodontal Plastic Surgery for Cosmetic Root Coverage: A Case Report. People's Journal of Scientific Research 2010; 3(2): 27-31.
9. Zucchelli G, De Sanctis M. Treatment of multiple recession-type defects in patients with esthetic demands. J Periodontol. 2000 Sep;71(9):1506-14
Address for correspondence:

Dr.Jananni.M

Senior Lecturer,

Department of Periodontology \& Implantology,

Indira Gandhi Institute Of Dental Sciences,

Puducherry.

\section{Authors:}

1 Senior Lecturer, Department of Periodontology \& Implantology, IGIDS, Puducherry.

2 Senior Lecturer, Department of Oral Pathology \& Microbiology, IGIDS, Puducherry

${ }^{3,4}$ Senior Lecturer, Department Of Periodontology. Meenakshi Ammal Dental College \& Hospital, Chennai.

${ }^{5}$ Tutor, Department of Periodontology \& Implantology, IGIDS, Puducherry.

\section{How to cite this article:}

Jananni.M, Sivaramakrishnan.M, Gubernath U, Anitha Logarangini, Lakshmi Priya. Zucchellie's Technique with GTR Membrane for Multiple Gingival Recession Coverage . Journal ofS cientific Dentistry 2013;3 (1):25-29

Source of Support: Nil, Conflict of Interest: None declared 